European Journal of Medical and Health Sciences, 3(4), 72-78, 2021

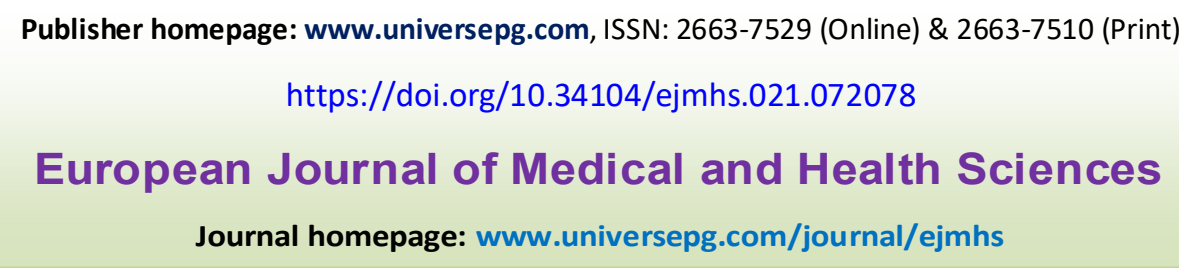

\title{
Studies on Behavioral Problem of Children: Effects of Occupational and Socio-demographic Characteristics of Working Mother in Dhaka City, Bangladesh
}

\author{
Nusrat Mustary ${ }^{1,2 *}$ and Md. Mahmudul Haque ${ }^{2}$ \\ ${ }^{1}$ Dept. of Community Medicine, Dhaka National Medical College, 53/1 Johnson Road, Dhaka 1100, Bangladesh; ${ }^{2}$ Dept. of \\ Community Medicine, National Institute of Preventive and Social Medicine (NIPSOM), Faculty of Preventive and Social \\ Medicine, Bangabandhu Sheikh Mujib Medical University, Dhaka-1000, Bangladesh. \\ *Correspondence: nusrat.dnmc@gmail.com (Nusrat Mustary, Dept. of Community Medicine, Dhaka National Medical \\ College, 53/1 Johnson Road, Dhaka 1100, Bangladesh).
}

\begin{abstract}
Problems associated with children are of great concern to the parents and to the nation. Especially, the behavioral problem of children originated from mother's life-style is crucial to study. In this study, the behavioral problem of children aged from 11 to 16 years in the capital city Dhaka of Bangladesh in terms of mother's occupational and socio-demographic characteristics was reported. An observational cross-sectional study was carried in Dhaka City from January 2014 to December 2014. Sampling was done by purposive method for both sexes willing to participate. Occupations (c.f. service, business, teaching, housemaid, and labor) in respect of the duration of work and length of service and socio-demography (c.f. age, education, family member, and income of mother) were accounted to identify the problems. The model findings would play a vital role to solve the behavioral problem of children which contributes to establishing a sustainable society for advanced nations.
\end{abstract}

Keywords: Behavioral problem, Children, Working mother, Effect, Occupational, and Socio-demographic.

\section{INTRODUCTION:}

Role of a mother to the family is mandatory especially for the children to develop a sustainable society. With the present demand of practical life, today's mothers are engaged with different professional activities. Therefore, the children are missing mother's contact during their growth which causes behavioral problem due to lack of proper training in terms of food habits, sleeping, spontaneity, class performance, and friend-ship patterns. Bangladesh is a promising country for economic growth due to the cumulative strength of both male and female's working capacity. The dynamic economic advancement of Bangladesh depends on the parallel participation of women in every sector which UniversePG I www.universepg.com changes their lifestyle today. Without their mutual performance, it is quite impossible to advance satisfactorily. Many research groups reported that Bangladeshi women actively involved in productive and non-productive activities and has been increasing day by day (Aeri, and Devina, 2010; Banks, 2010, 2013; Francesca, 2010; Lantara, 2015; Rumana, 2012). Almost all Bangladeshi women play a double role. They play role of mother at home and as a labor force at work place. Rural women work to manage family maintenance at home ground mainly for cooking, washing, cleaning, yard-work and child care etc. Besides, mothers in the city usually experienced with different professions which control their life style and modify their attitude 
as well. Generally, a mother spends maximum time with her child from birth relative to any other member of the family, therefore an extremely strong influence on child in the matter of attitudes, abilities and behavior is reflected due to mother's interaction and instructions involvement. Favorable parental attitudes and a wholesome relationship existed between children and parents helps to develop well-adjusted and better friendly behavior of their children successfully (Rumana, 2012; Salam and Aktar, 2020; Banks, 2010, 2013).

From the very beginning of a children's life love, affection and care are primary need for their growth therefore maximum numbers of countries in the world have taken this matter as a major issue due to building their nation. In general, mother fulfills basic requirements of a child, therefore a strong believes and dependency slowly develops on her to get care, devotion and affinity. Selection of a job to work out of home yard or taking care of child at home is certainly a very crucial and hard decision for a mother. A mother usually faces many questions and situation before taking decision for her lifestyle. After considering the needs of children at home, financial strength of her family, a mother would take decision. Sometimes job nature, work load emphasizes to choose their pathway. High ambition of a woman for establishing her name and fame originated from strong credentials would create complex situation in the family to decide whether she works for supporting family or for her name and fame. Finally, if a mother takes a challenge, she will find a suitable job which fulfills her desire, such as saves time and energy and provides required financial assistance, name and fame (Aeri, and Devina, 2010; http:// www.livestrong.com, 2010).

Shalala expressed that women in the current era are passing very difficult situation. They are diverted in many directions after facing diversified challenges. Some women are concentrating to put all their whole efforts to build their personal careers, but some a wait until their children become around the school ages. Depending on financial matter, some women have their own choice of employment while others are forced to work (Aeri, and Devina, 2010; http://www. livestrong.com, 2010). The study aims to observe improper care, training of working mothers has any effects on her children's growth and development UniversePG I www.universepg.com which could exerts in children as behavior problem in future. Here behavioral problem is defined as any sort of deviation from normal state. Behavioral problem of children could be related with nursing procedure following at early age of children.

\section{MATERIALS AND METHODS:}

An observational cross-sectional study was carried out in Dhaka City from January, 2014 to December, 2014 considering children age from 11 to 16 years. Sampling was carried out by purposive method for both sexes willing to take part in this study. Data were collected in a pre-designed questionnaire by face to face interview.

Sample structure - The sample size was determined by the following equation -

$$
n=\frac{z^{2} \times p q}{d^{2}}
$$

Where, $\mathrm{n}=$ the desired sample size

$\mathrm{Z}=$ the standard normal deviate, set at 1.96 at $5 \%$ level which corresponded to $95 \%$ confident level

The assumed target population was $\mathrm{P}$ to have a particular characteristic and $\mathrm{q}=1-\mathrm{p}$

Here, $\mathrm{P}=0.50$ (From previous study stated in literature review)

$\mathrm{D}$ is the allowable error which is $10 \%$ of $\mathrm{P}$ i.e. $10 \%$ of $0.05=0.005$

Considering the values in the above equation, desired sample size $n$ was calculated as -

$$
n=\frac{(1.96)^{2} \times 0.5 \times 0.5}{(0.05)^{2}}=384
$$

So the sample size was 384 , but due to the limitation of time data were collected from 171 respondents.

Ethical implication - From the respondents, an informed written consent in Bangla was used for securing their participation. To avoid complexity and to maintain its simplicity and clarity, an English version of consent form was first drafted and then translated into Bangle. Moral approval was taken from ethical review committee of the institute. This prescribed study was run through collection of data using preset questionnaire and checklist. Neither any intervention nor any invasive procedures were applied. Before initiation of the interview the consent form was read out which included aims and objectives, reason for invitation, expectation from the respondents, risks and benefits, 
confidentiality of data etc. The participants were well informed about their full right to take part or to refuse it. We have ascertained the participants that all information would be kept confidential and their name or anything would not be published or exposed anywhere. Their participation and contribution would be acknowledged with due respect. Data were collected from those only who consented.

\section{RESULTS AND DISCUSSION:}

An observational cross-sectional type of descriptive study about behavioral problem in adolescent aged (11-16 years) of working mother was regulated in Dhaka city, Bangladesh from January, 2014 to December, 2014. The study was aimed to inspect behavioral problem in adolescent aged (11-16 years) of working mother through existing socio demographic, socioeconomic factors of mothers and a scale on behavioral problem of children. A total 200 children were selected purposively were selected for the study. A set of questionnaire was used to interview the children.

Relationship between behavioral problem of children and occupational characteristics - From the Table 1, it is evident that the fraction of high need behavioral problem was the maximum among children whose mother was teacher and the minimum among children whose mother was housewife whereas, $43.6 \%$ and $40.9 \%$ of high need behavioral problem was remarkably high among children whose mother occupation was business and service respectively. On the other hand, the percentage of low need behavioral problem was significantly high among children whose mother was housewife $(53.1 \%)$ and the lowest among children whose mother occupation was business $(20.5 \%)$ while $34.3 \%$ and $38.6 \%$ of low need behavioral problem was among children whose mother occupation was teacher and service respectively. Occupation of mother was significantly associated $(\mathrm{p}=0.028)$ with behavioral problem of children (Table 1).

The mentioned finding is well suited with already published analysis of (Moataz et al., 2004), who reported on prevalence and concerned risk factors for emotional and attitude problems within school going boys and girls. They also reported that mother's occupation as one of the most important influencing factors of developing emotional and behavioral disturbances to their children. (Hobfoll et al., 2003), also claimed almost resemble results that scale of behavioral problems of children depend on mother's fatigue and unhappiness arose due to her employment environment.

Table 1: Relationship between behavioral problem and occupation of the mothers.

\begin{tabular}{c|ccc|c|c}
\hline \multirow{2}{*}{ Occupation } & \multicolumn{3}{|c|}{ Behavioral problem } & \multirow{2}{*}{$\chi^{2}$} & \multirow{2}{*}{ P } \\
\cline { 2 - 5 } & Low need & Some need & High need & & \\
Service & $38.6 \%$ & $20.5 \%$ & $40.9 \%$ & & \\
Business & $20.5 \%$ & $35.9 \%$ & $43.6 \%$ & 17.23 & \\
Teacher & $34.3 \%$ & $11.4 \%$ & $54.3 \%$ & & \\
Housewife & $53.1 \%$ & $24.5 \%$ & $33.3 \%$ & & \\
Laborer & & & 42.4 & & \\
\hline
\end{tabular}

Relationship between behavioral problem and duration of work - The Table 2 shows that the segment of high need behavioral problem was the highest among children whose mother's duration of work exceeded 8 hours $(59.0 \%)$ and the lowest among children whose mother's duration of work was 6 hours or less (20.4\%) while $37.6 \%$ of high need behavioral problem was observed among children whose mother's duration of work was 8 hours. On the other hand, proportion of low need behavioral problem was the highest among children whose mother's duration of work was 6 hours or less $(53.5 \%)$ and proportion of low need behavioral problem decreases with the increase of duration of work of respective children's mother. Duration of mother's work was significantly associated $(p=0.001)$ with behavioral problem of children (Table 2).

Relationship between behavioral problem of children and length of service - Working period of mother also influence the children behavior as shown in Table 3. It is revealed that the number of high need behavioral problem was the highest among children whose mother's length of service was more than 10 years $(46.3 \%)$ and the lowest among children whose 
mother's service length was 5 years or less (27.9\%) besides $37.1 \%$ of high need behavioral problem was found among the children whose mother's service length was 5 to 10 years. Besides, low need behavioral problem was the highest among children whose mot- her's length of service was 5 to 10 years (40.3\%) and was the lowest among children whose mother's length of service was more than 10years (34.7\%). Length of service of mother was not significantly associated $(\mathrm{p}=$ 0.183 ) with behavioral problem of the children (Table 3 ).

Table 2: Relationship between behavioral problem and duration of work.

\begin{tabular}{c|ccc|c|c}
\hline \multirow{2}{*}{ Duration of work } & \multicolumn{3}{|c|}{ Behavioral problem } & \multirow{2}{*}{$\chi^{2}$} & \multirow{2}{*}{ P } \\
\cline { 2 - 4 } & Low need & Some need & High need & \\
\hline 6 hours or less & $53.7 \%$ & $25.9 \%$ & $20.4 \%$ & \multirow{2}{*}{19.541} & 0.001 \\
8 hours & $35.5 \%$ & $27.1 \%$ & $37.6 \%$ & \\
More than 8 hours & $24.6 \%$ & $16.4 \%$ & $59.0 \%$ & & \\
\hline
\end{tabular}

Table 3: Relationship between behavioral problem and length of service.

\begin{tabular}{c|ccc|c|c}
\hline \multirow{2}{*}{ Length of service } & \multicolumn{3}{|c|}{ Behavioral problem } & \multirow{2}{*}{$\chi^{2}$} & \multirow{2}{*}{ P } \\
\cline { 2 - 4 } & Low need & Some need & High need & \multirow{2}{*}{0.183} \\
\hline 5 years or less & $37.2 \%$ & $34.9 \%$ & $27.9 \%$ & 6.219 & \\
5-10 years & $40.3 \%$ & $22.6 \%$ & $37.1 \%$ & & \\
More than 10 years & $34.7 \%$ & $18.9 \%$ & $46.3 \%$ & & \\
\hline
\end{tabular}

Relationship between behavioral problem and socio demographic characteristics

Relationship between behavioral problem of children and age of mother - The effect of mother's age on children attitude is furnished in the Table 4 (Jong et al., 2012). We have found that proportion of high need behavioral problem was highest among the children whose mother's age was more above 40 years (46.4\%) and lowest among the children whose mother age was 31 to 40 years $(34.3 \%$ ) while $42.3 \%$ of high need behavioral problem was among the children whose mother age was below 30 years. Oppositely, population low need behavioral problem was the highest among children whose mother's age was 31 to 40 years $(47.6 \%)$ and the lowest among kids whose mother's age was more than 40 years $(23.2 \%)$. It is found that the age of mother was significantly associated $(\mathrm{p}=0.022)$ with behavioral problem of children (Table 4). The results of this research work are incongruent with the data acquired by (Divya, 2009). A significant association ( $p$ $<0.05$ ) with the behavioral problems of children of working mothers is shown by considering age of the child, gender, number of children, type of family and birth order.

Table 4: Relationship between behavioral problem and age of the mother.

\begin{tabular}{|c|c|c|c|c|c|}
\hline \multirow[b]{2}{*}{ Age } & \multicolumn{3}{|c|}{ Behavioral problem } & \multirow[b]{2}{*}{$\chi^{2}$} & \multirow[b]{2}{*}{$\mathbf{P}$} \\
\hline & Low need & Some need & High need & & \\
\hline Below 30 years & $30.8 \%$ & $34.9 \%$ & $27.9 \%$ & & \\
\hline $31-40$ years & $47.6 \%$ & $22.6 \%$ & $37.1 \%$ & 11.478 & 0.022 \\
\hline Above40 years & $23.2 \%$ & $30.4 \%$ & $46.4 \%$ & & \\
\hline
\end{tabular}

Relationship between behavioral problem of children and education of mother - Educated mothers are too busy because they play double role in our society therefore the contact time between mother and children. The impact level of mother's education on children behavior is inserted in Table $\mathbf{5}$ and it is found that the number of high need behavioral problem was the highest among children whose mother's edu-cation was masters completed (48.5\%) and the lowest among

UniversePG I www.universepg.com children whose mother education was below SSC (27. 9\%) while $38.5 \%$ and $37.6 \%$ of high need behavioral problem was among the children whose mother education was SSC and HSC, respectively. In other words, proportion of low need behavioral problem was the highest among children whose mother's education was SSC completed (46.2\%) and was the lowest for children whose mother's education was HSC completed (24.1\%) besides, $40.6 \%$ and $30.8 \%$ of low need be- 
havioral problem was among children whose mother's education was honors completed and below SSC, respectively. Education of the mother was not signifi- cantly associated $(\mathrm{p}=0.422)$ with behavioral problem of the children (Table 5).

Table 5: Relationship between behavioral problem and education of mother.

\begin{tabular}{c|cc|c|c|c}
\hline \multirow{2}{*}{ Level of Education } & \multicolumn{3}{|c|}{ Behavioral problem } & \multirow{2}{*}{$\boldsymbol{\chi}^{2}$} & \multirow{2}{*}{ P } \\
\cline { 2 - 4 } & Low need & Some need & High need & & \\
Below SSC & $30.8 \%$ & $26.9 \%$ & $27.9 \%$ & & 0.422 \\
SSC & $46.2 \%$ & $15.4 \%$ & $38.5 \%$ & 8.122 & \\
HSC & $24.1 \%$ & $37.6 \%$ & $37.6 \%$ & & \\
Honors & $40.6 \%$ & $25.0 \%$ & $34.4 \%$ & & \\
Masters & $36.2 \%$ & $15.5 \%$ & 48.9 & & \\
\hline
\end{tabular}

Relationship between behavioral problem and family member - Bangladesh is a populated country, and the Government has taken several attempts to control the family members because the demand of family to continue a standard condition is high which is very difficult for a low income parent who disturbs to create good atmosphere in the family and originates problems of the children behavior as shown in Table 6. In this research work, it is revealed that the proportion of high need behavioral problem was the highest among children with more than 10 family members $(68.4 \%)$ and proportion decreases with the decrease of number of family members while lowest among the children with family member 1 to 3 (29.7\%). Proportion of some needed behavioral problem was the highest among children with family members 1 to $3(32.4 \%)$ and pro- portion increases with the increase of number of family members while the lowest among children with family members more than $10(10.5 \%)$. On the other hand, proportion of low need behavioral problem was the highest among children with number of family members 4 to $6(43.5 \%)$ and the lowest among children with family members more than $10(21.1 \%)$. It is also found that $37.8 \%$ and $25.0 \%$ of low need behavioral problem was reported among children with family members 1 to 3 and 7 to 9 , respectively. The number of mother's family members was significantly associated $(\mathrm{p}=0.017)$ with behavioral problem of children (Table 6). It is revealed that in (Alexander and Asha, 2014) found maximum $53.3 \%$ of working mothers and 46.7\% of non-working mothers lived in nuclear family and joint family respectively.

Table 6: Relationship between behavioral problem and number of family members.

\begin{tabular}{c|cc|c|c|c|}
\hline \multirow{2}{*}{ Number of family members } & \multicolumn{3}{|c|}{ Behavioral problem } & \multirow{2}{*}{$\chi^{\mathbf{2}}$} & \multirow{2}{*}{ P } \\
\cline { 2 - 4 } & Low need & Some need & High need & & \\
$4-3$ & $37.8 \%$ & $32.4 \%$ & $29.7 \%$ & & \\
$4-6$ & $43.5 \%$ & $24.1 \%$ & $32.4 \%$ & & 0.017 \\
$7-9$ & $25.0 \%$ & $19.4 \%$ & $55.6 \%$ & 15.481 & \\
$10^{+}$ & $21.1 \%$ & $10.5 \%$ & $68.4 \%$ & & \\
\hline
\end{tabular}

Relationship between behavioral problem of children and income of mother - Financial strength is a crucial factor to run the family smoothly (Alexander and Asha, 2014; Gennetian et al., 2008). The fulfillment of basic need of a family depends on their monthly income. Mother's contribution to the financial strength of a family regarding the behavioral problem of children is shown in Table 7. It is revealed that the fragment of high need children's behavioral problem was $48.1 \%$ regarding mother income up to 10,000 taka (118 USD) and $32.5 \%$ among children with mother income above 50,000 taka (588 USD). The population of UniversePG I www.universepg.com some need behavioral problem was $28.1 \%$ among the children with mother's income 20,001 (235 USD)) to 50,000 taka (588 USD) and ca. $11 \%$ among the children with mother's income up to 10,000 taka (118 USD). The low need behavioral problem was the highest (47.5\%) among children with mother's income above 50,000 taka (588 USD) and the lowest (31.3\%) among children with mother's income between 20,001 to 50,000 taka. It is evident that income of a mother was not significantly associated $(p=0.414)$ with behavioral problem of a child (Table 7). 
Table 7: Relationship between behavioral problem and monthly income of mother.

\begin{tabular}{c|c|c|c|c|c}
\hline \multirow{2}{*}{ Monthly income } & \multicolumn{3}{|c|}{ Behavioral problem } & \multirow{2}{*}{$\chi^{2}$} & \multirow{2}{*}{ P } \\
\cline { 2 - 4 } & Low need & Some need & High need & & \\
\hline Upto 10,000 tk & $40.7 \%$ & $11.1 \%$ & $48.1 \%$ & & \\
$10,001-20,000$ tk & $37.8 \%$ & $24.3 \%$ & $37.8 \%$ & & 0.414 \\
$20,001-50,000$ tk & $31.3 \%$ & $28.1 \%$ & $40.6 \%$ & 6.079 & \\
$50,000^{+} \mathrm{Tk}$ & $47.5 \%$ & $20.5 \%$ & $32.5 \%$ & & \\
\hline
\end{tabular}

\section{CONCLUSION:}

Among the occupations, children of mothers having teaching profession show the highest percentage of behavioral problem and housemaid mothers shows the lowest percentage behavioral problem. Based on duration of work, it is revealed that the children of whose mothers involved with work more than $8 \mathrm{hrs}$. Found the highest percentage of behavioral problem and involved with less than $6 \mathrm{hrs}$ of works has the lowest percentage of that problem. Furthermore, considering the length of services, more than $10 \mathrm{hrs}$ working mothers have children with the highest percentage of behavioral problem. The least percentage of children's behavioral problem was identified whose mother's length of service is between 5-10 hrs. Considering the sociodemographic characteristic of a mother, we have found that the children whose mother's age are above 40 years, have the highest percentage of behavioral problem and between 31-40 years of age have the lowest problem. Mothers who awarded Master degree have children of the highest percentage of behavioral problem and mother's education below secondary level has children with the lowest percentage of behavioral problem. Finally, these data would reflect, the behavioral pattern of upcoming youth of Bangladesh and imply the necessary measures to be taken for future development.

\section{ACKNOWLEDGEMENT:}

The authors are highly acknowledged to the participants whose direct support made the research project successful.

\section{CONFLICTS OF INTEREST:}

The authors declared there was no conflict of interests.

\section{REFERENCES:}

1) Aeri, and Devina, J., (2010). Effect of Employment Status of Mothers on Conceptual Skills of Preschoolers, Department of Human Develop-

UniversePG I www.universepg.com ment, Guru Nanak Girls College, Yamuna Nagar, Haryana, India. Raj, J. Soc. Sci, 24(3) 213-215.

2) Alexander, A., Asha, P S., (2014). A comparative study on behavioral problems of preschool children among working and non-working mothers, IOSR J. of Nurs. and Heal. Sci. 3(6) 35-38. http://www.livestrong.com/article/10.9790/1959$\underline{03613538}$

3) Banks, N., (2010). Employment and mobility among low-income urban households in Dhaka, Bangladesh", unpublished PhD thesis, University of Manchester, 25(1): 95-109. https://doi.org/10.1177/0956247813477357

4) Banks, N., (2013). Female employment in Dhaka, Bangladesh: participation, perceptions and pressures, Environment and Urbanization, Intern. Ins. for Env., and Develop., 25(1) 95-109. https://doi.org/10.1177/0956247813477357

5) de Jong, M.,Verhoeven, M.,van Baar, A. L., (2012). School outcome, cognitive functioning, and behaviour problems in moderate and late pre-term children and adults: a review. Semin Fetal Neonatal Med. Jun; 17(3) 163-169. https://doi.org/10.1016/j.siny.2012.02.003

6) Divya, A., (2009). A study to assess emotional and behavioral problems of children (6-12 years) of working mothers in selected schools, Mangalore. Unpublisheddissertation submitted toRGUHS.

7) Francesca, F., (2010). The relation between child work and the employment of mothers in India, International J. of Manpower, 31, 232-257. https://ideas.repec.org/a/eme/ijmpps/v31y2010i2p2 32-257.html

8) Gennetian, L., Lopoo, L., London, A., (2008). Maternal work hours and adolescents' school outcomes among low-income families in four urban counties. Demography, 45(1) 31-53. https://doi.org/10.1353/dem.2008.0003

9) Hobfoll, S.E., Johnson, R. J.,Ennis, N.,Jackson, A. P., (2003). Resource loss, resource gain, and 
emotional outcomes among inner city women, $J$ PersSoc Psychol. Mar; 84(3): 632-643.

http://www.livestrong.com/article/269947 "staying at home vs a working mom

10) Lantara, N.F., (2015). The Roles of Woman as Leader and Housewife. J Def Manag 5, 125. https://doi.org/10.4172/2167-0374.1000125

11) Moataz, M., Fattah, A., Arafa, M. A., (2004). Emotional and Behavioral Problems Among Male Saudi Schoolchildren and Adolescents Prevalence and Risk Factors, Reprinted from the German Journal of Psychiatry, 9(4):299-306.
12) Rumana, A., (2012). Changing Expectations of Gender Roles in Bangladesh: The Case of Female Field Staff of BRAC. http://research.brac.net/monographs/Workplacewo menfriendly.pdf

13) Salam S., and Aktar B. (2020). Child marriage in rural Bangladesh and its consequences on reproductive and maternal health: an empirical study, Eur. J. Med. Health Sci., 2(4), 74-85. https://doi.org/10.34104/ejmhs.020.074085

\section{SUPPLEMENTARY FILE}

This form is to be filled up by a young person between 11 and 16 years old Questionnaire.

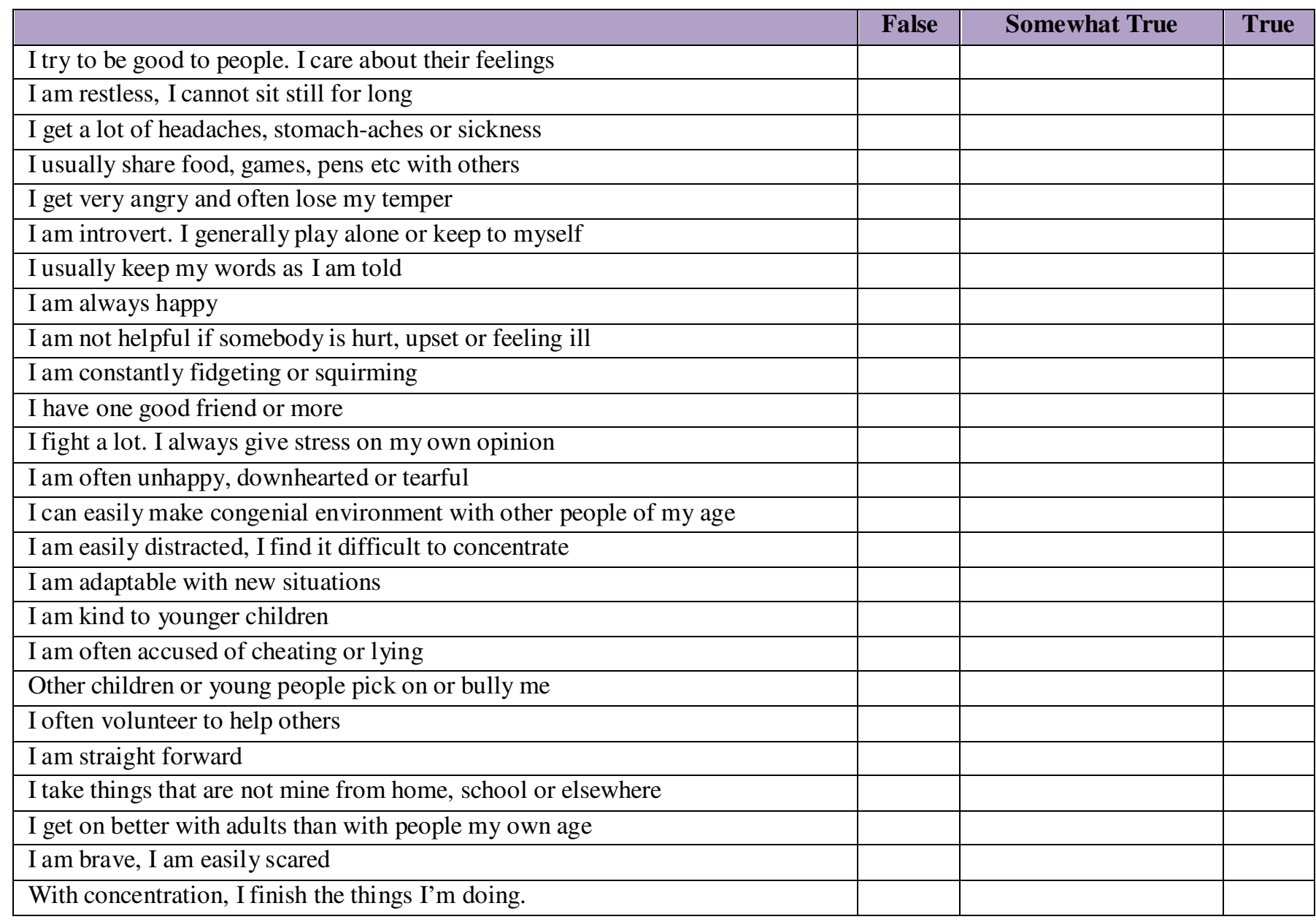

Citation: Mustary N., and Haque MM. (2021). Studies on behavioral problem of children: effects of occupational and socio-demographic characteristics of working mother in Dhaka city, Bangladesh, Eur. J. Med. Health Sci., 3(4), 72-78. https://doi.org/10.34104/ejmhs.021.072078 @) 